\title{
Promoting Social Justice through Storytelling in Museums
}

\author{
Arianna Huhn, Annika Anderson
}

\begin{abstract}
In 2018 the Anthropology Museum at California State University San Bernardino (USA) opened an exhibition entitled In|Dignity. The collaborative endeavour combined social science techniques, documentary photography, and theatre performances to present first person narratives of 43 community members. Participants represented marginalized demographics and intersectional identities that extended far beyond standardized approaches to 'diversity'. Their stories provided an intimate look into experiences of discrimination, microaggressions, harassment, exclusion, and other affronts to self-worth and barriers to community belonging. This article argues that connecting individuals through telling and listening to stories is a valid strategy to promote social justice. In|Dignity provides one case study of a museum using the narrative form and the processes of exhibition development to disrupt power hierarchies, uplift community concerns, and promote human dignity.
\end{abstract}

Key words: Social Justice; Oral History; Storytelling; Community; University Museums; Exhibit Co-creation

\section{Introduction}

The year 2020 will be remembered for many events, some of which the world would rather forget. But if there is a bright spot, it is the way in which disparities highlighted by the COVID-19 pandemic and police violence have broadened support for social justice. The latter movement advocates for compassionate distribution of resources and power, equitable participation in processes of economic growth, and the redesign of institutions, systems, and policies to support equal rights, opportunities, and treatment for everyone. Battles against cultural domination, stereotyping, imperialism and erasure contribute to social justice goals as well (Fraser 1997; North 2006; Cho 2017). In each of these arenas, individuals and institutions in positions of privilege are asked to look introspectively and use their resources to support systemic change.

While long considered outside the purview of museum interests and operations, active engagement with social justice has over the last several decades become increasingly mainstream (Witcomb 2003; Reilly 2018; Janes and Sandell 2019; Chynoweth et al. 2020). This has been thanks, in part, to efforts spearheaded in the 1990s and early 2000s by professional museum organizations (for example, Hirzy 1992), but also the hidden labour of individual museums and practitioners who pushed the agenda forward at the grassroots level (Jennings and Jones-Rizzi 2017). More recently the mantle has been taken up by independent coalitions like Museum Hue, Incluseum, and Museum Commons. A clear sign of sea change, in 2019 the International Council of Museums proposed a modification to the definition of the word 'museum' to emphasize the integral nature of inclusivity and social justice for the field. ${ }^{1}$ The move has been controversial. Pushback centres on accusations of misinformation, propaganda, and fabrication or distortions of facts to suit progressive agendas, as well as the inappropriateness of abandoning objectivity to support social ends (Sandell 2002; Cameron 2007; Nightingale and Sandell 2012; Arnold-de Simine 2013; Orloff 2017; Ng 
et al. 2017; Gonzales 2020). ${ }^{2}$ More recently, the deaccession and sale of collections to fund social justice initiatives has come under fire from the public and professional organizations. ${ }^{3}$

Regardless of whether museums should engage in social justice work (we strongly believe the answer is 'yes'), their potential to do so is immense. Preliminary research suggests that museums have the capacity to 'reconfigure normative moral codes' in support of progressive human rights values (Sandell 2012); create transformative spaces where visitors are encouraged to cross boundaries of belonging and engage in intercultural dialogue ${ }^{4}$ spark challenging conversations (Ellis 1995; Cavness 2019); position viewers in ways that precipitate critical consciousness regarding the ethical character of daily life (Bonnell and Simon 2007); and otherwise serve as sites for 'critical pedagogy' (Freire 1968) in which seeds can be planted 'for renegotiating hegemonic relations' (Mayo 2013). These capacities are related to positive public perceptions of museums as trustworthy sources of objective information, ${ }^{5}$ making them safe and supportive atmospheres for meaningful experiences.

The authors of this article support a place for social justice within the heart of museum operations. We focus on distributive justice (more equitable inclusion) and redistributive justice (mitigating prejudice), and we argue that connecting individuals through narrative storytelling is a form of social justice work that can and should be undertaken by museums. After briefly reviewing the relationship between social justice, storytelling, and collaboration, we present and reflect on our work curating a narrative-based and community-centred exhibition designed to infuse a social justice agenda into standard exhibitionary practices and to amplify voices from our community.

\section{Curating for Social Justice}

Over the last several decades, scholars have traced the roots of cherished museums in oppression, prejudice, and inequality, while illuminating the role of contemporary museology in perpetuating these phenomena. In response, many museums have engaged in critical institutional inquiry - asking how contemporary policies and practices perpetuate problematic legacies and calling out the cultural norms, popular ideas, and historical patterns that undergird disparities (Bennett 1995; Hooper-Greenhill 1992, 2008; Lynch and Alberti 2010: 13-4; Fischer et al. 2017; Jennings and Jones-Rizzi 2017: 72-3). In the area of exhibitions, familiar, triumphant, and patriotic stories that offer discursive closure based on approved knowledge have been questioned as elitist and exclusionary, and new strategies have been developed for leaning into difficult subjects that complicate reality, expose dissent and ignite uncomfortable conversations (Bonnell and Simon 2007; Teslow 2007; Lynch and Alberti 2010; Simon 2011; Mayo 2013; Adams 2017).

Such an approach to curatorial work is not only inherently controversial, but it must be undertaken with great care so as not to unintentionally perpetuate the exploitation, exclusion, and disempowerment it is intended to redress (Peers and Brown 2003; Chynoweth et al. 2020). Tracy Teslow (2007) writes, for example, of an exhibition that was conceived as transgressive in showcasing portraits of poor black men in a dignified manner. But the men were presented anonymously, making the exhibition seem less about demanding 'dignity and empowerment' for the marginalized than 'capitalizing on commerce in blackness' (Teslow 2007: 28). A formulaic and opportunistic 'spectacle of suffering' (Bonnell and Simon 2007: 74) does not broaden representation or dismantle the status quo; the approach only reinforces existing problematic practices. Cassandra R. Cavness (2019) similarly compares two museums in Montgomery, Alabama: the Legacy Museum and the Museum of Alabama. The former unabashedly confronts visitors with the harsh realities of slavery and the injustices of the contemporary American legal system. The latter, Cavness argues, uses insensitive design choices that can make visitors feel unwelcome - for example, slave shackles paired with a text panel that focuses on the games played by enslaved children, and a cotton gin accompanied by imagery celebrating entrepreneurship. Such representation can do more harm than good.

To avoid offensive missteps, but more importantly to truly embrace a social justice agenda, the museum field has moved toward developing exhibitions in collaboration with individuals who identify with the objects and subjects in question (Karp et al. 1992; Peers and Brown 2003; Golding and Modest 2013; Ng et al. 2017). Community members are asked 
to contribute objects, knowledge, and opinions to extend involvement to a broader and more inclusive range of stakeholders and to enhance accountability. But even museums with the best of intentions have experienced challenges in promoting equitable and inclusive participation, noting for example the fraught nature of determining who counts as a 'stakeholder' (Bruner 1996), navigating situations where community preferences mirror hegemonic positionings or otherwise clash with curatorial expertise (Momaya 2018), reorienting staff members from approaching engagement as something to be 'dealt with', 6 and overcoming power differentials inherent in working with marginalized populations (Watson 2007; Lynch and Alberti 2010). Another challenge is recognizing diversity within populations rather than assuming that the most vocal, visible, or economically privileged represent an entire community.

Museums have also been criticized for constructing opportunities for participation disingenuously - as a veneer of authentic 'voices' invited only to lend credibility to predetermined storylines, policies, and practices (Chynoweth et al. 2020). Gretchen Jennings and Joanne Jones-Rizzi (2017: 71-2) similarly point out that where community engagement is an institutional strategy for extracting information (versus a process for generating knowledge and relationships), divisions of insiders and outsiders are perpetuated and can lead to communities feeling exploited rather than respected and valued. Bernadette Lynch (2020) argues that in order for a museum to be truly 'helpful' there is a need not just to 'engage' the community, but to be more deliberate in supporting empowerment and capacity building, treating partners as active agents rather than passive beneficiaries, and strategizing more deliberately to share intellectual control.

One method that museums have used to prioritize community concerns, expertise, and experiences (and thus to create a more hospitable environment for fostering genuine collaborations (Gonzales 2020)), is centring exhibitions on oral testimony. Although autobiographical narratives were traditionally perceived to conflict with museums' objectfocused modus operandi (Griffiths 1989; Baxter and Marshall 2012), many now support storytelling as an effective strategy for broadening interpretations and curatorial foci (Roberts 1997; McDonnell 2003; Green 2007; Day 2009; Bedford 2010, 2014; Adair et al. 2011; Baxter and Marshall 2012: 61; Lowry and Duke 2015). Approaches have been diverse and creative, including exhibitions based entirely on personal narratives. These might use recorded stories in interactive elements, public performances based on oral history, and docents sharing their first-hand experiences directly with visitors (Perks 1991; Kushner 2001; Day 2006; Tongo 2006; Julius 2008; Arnold-de Simine 2013).

Research on 'counter-storytelling' (autobiographical narratives by those whose existence and experiences are silenced or made invisible by mainstream society) stresses that the opportunity to speak one's truth, and to de-naturalize and de-centre majoritarian stories, can empower storytellers (Solórzano and Yosso 2002; Wagaman et al. 2018). Such narratives can have profound impacts on story listeners as well, facilitating radical listening (Heldke 2006) and emotional engagement in ways distinct from cognitive inquiry (Bonnell and Simon 2007; Simon 2011; Fischer et al. 2017). While the effects of storytelling on museum visitors are poorly documented (Arnold-de Simine 2013), research from other fields demonstrates that narratives trigger the release of neurochemicals that support attentiveness, understanding, and action (Zak 2015); make information more memorable; and generate less defensive responses from listeners than other forms of communication (Bruner 1990). Decades of sociological research on the 'contact hypothesis' further clarifies that intergroup encounters with perceived 'Others' are an effective strategy for reducing generalizations and oversimplifications, including misconceptions and stereotypes (Allport 1954; Pettigrew and Tropp 2006; Dovidio et al. 2011).

Silke Arnold-de Simine (2013) warns that there could be a danger in using narratives to elicit 'empathetic distress' from museum visitors: reliance on emotional connections, she argues, can lead to overlooking broader, contextual forces that explain why personal suffering takes place and dismissing one's responsibility to act to address them. But Jennifer Bonnell and Roger I. Simon (2007) argue that the goal of storytelling in museums is not that visitors come to identify with the storyteller so much as they acknowledge and dwell upon how much they do not know the storyteller. In this way, listening to personal narratives has the potential to initiate a 'reflexive critique and transformative insight' in one's own complicity 
in the peddling of established certainties and related moral groundings (Bonnell and Simon 2007: 69). While both perspectives are more theoretical than incontrovertible, even Arnolde-de Simine concedes that there is a value in the way storytelling promotes an acknowledgment of human vulnerability. And for this, she suggests, 'the museum is a good place to start' (Arnolde-de Simine 2013: 125).

The use of oral testimony in museums is part of broader trends in affective curation (Gokcigdem 2016, 2019; Gonzales 2020), an approach to exhibition design that Teslow (2007) traces to the 1987 exhibition From Field to Factory, which required visitors to acknowledge racial differences by passing between one of two doors - one marked 'colored' [sic] and the other marked 'white'. Elena Gonzales (2020) draws from neuroscience to argue that such museum-enabled, embodied, emotional responses can result in long-lasting memories, which are more likely than others to engender fellow-feeling and critical thinking that lead to action. In this way affective curation has the potential for personal and societal transformation, drawing on the power of emotion as integral to the development of critical consciousness (Langstraat and Bowdon 2011: 9).

\section{In|Dignity: Advocating for and Practicing Social Justice}

The desire to bring a social justice agenda to bear on exhibition development led the authors of this article to curate an exhibition called In|Dignity. We developed the show for the Anthropology Museum, a small gallery at California State University San Bernardino (CSUSB), where we are faculty members. The name In|Dignity is a double entendre simultaneously reading as a single word ('indignity') and two separate words ('in dignity'). These meanings capture precisely what the exhibition explored: experiences with oppression, discrimination, and prejudice, and simultaneously the pride and self-respect that we must have for ourselves and others facing injustice.

Our goal was to amplify the 'concealed stories' in our community, those that are in plain sight but are unseen or ignored (Bell 2010). These stories often feature individuals who lack the political clout, class status, or cultural capital to make their voices heard, or to ask to be heard, and whose experiences are deemed by mainstream society to be unworthy of interest or exposure (i.e. Paolo Freire's 'culture of silence'). The stories were derived from 42 interviews (43 individuals, two of whom were interviewed together) that we conducted with persons who live and work in our service area - San Bernardino and Riverside counties. ${ }^{7}$ This region is predominantly working class, and our university serves primarily first-generation students. At the inception of In|Dignity, our region was facing the one-year anniversary of a mass shooting, and this inspired a strong desire for messages of hope, unity, and mutual understanding.

Of note, the stories presented through In|Dignity are a sampling from our community, not a community, a departure from many museum-community partnerships that focus on working with representatives of a single demographic or other predefined group. Participants were recruited through community events, Facebook messaging to local affinity organizations, student recommendations, and word of mouth. Our communications simply asked for individuals who identified as 'marginalized' and wanted to share their story. We invited everyone who contacted us to be interviewed, with the exception of one individual who was below the approved minimum age for participation.

While we initially intended for student interns to lead our interviews, scheduling conflicts made this unfeasible. We briefly considered a method whereby community members would interview one another, and several students contributed to our project in this way. However, the university constrained our capacity to use this material unless all interviewers underwent human subjects protection training. Recognizing that this could diminish participation and would extend our timeline beyond the grant period, we decided to conduct the interviews ourselves, wherever possible with participation of student interns. Our experience serves as an example of the ways in which bureaucratic and structural barriers can limit participatory collaborations.

Our interviews were guided by, but not confined to, a list of eleven open-ended questions that we developed through student input and experimental interviewing in three courses. The 
semi-structured nature of our protocol allowed us to follow the direction of conversations as they unfolded, a technique Carolyn Ellis and Chris Patti (2014) call 'compassionate interviewing'. The method allowed each participant to speak their own, unbounded truth without the limitations of data collected for quantitative or comparative analysis. This is one way we sought to embody social justice in practices that promote multiplicity, collaboration and redistribution of power.

Our exhibition development process began by transcribing the 42 interviews, followed by open coding (a standard social science technique for narrative analysis) to form a list of major ideas and concepts for each interview. Three persons (the two authors, and one intern) coded each interview. The codes were then compiled and, over the course of three meetings, grouped to identify seven broad themes that became our framework for the exhibition. We then distributed the 42 interviews among the themes. Consequently, the organization of the exhibition emerged directly from participants' words and experiences, rather than a preconceived academic storyline onto which we overlaid and limited personal narratives.

\section{Petrified}

Personal stories from individuals whom our social upbringing often tells us to fear, to disparage, and avoid.

\section{Embodied}

Our bodies can bind us and free us, and outward appearances can reveal and conceal what is inside of us.

\section{Color Lines}

The significance of color in our lives - including how color can be used to divide, to unite, and to celebrate humanity.

Invisible

Being ignored, hidden, or muted affects identities and lived experiences.

Stones May Rot

Words influence self-perceptions and propel life decisions, in the moment and over time.

I Raise Up My Voice

Societal expectations of women, and experiences breaking the mold and crafting opportunities for empowerment, self-definition, and advancement.

\section{Empowered}

Experiences, wisdom, and requests for support in the pursuit of social justice.

\section{Table 1: In|Dignity's Seven Themes}

We did initially consider organizing the narratives using such academic concepts as intersectionality, microaggressions, and implicit bias. However, we quickly recognized the risk this presented for privileging 'expert knowledge' over lived experience and the potential limitations on participants speaking for themselves. As a museum on a university campus, we were also keenly aware that reliance on disciplinary jargon might impact perceptions of accessibility. As voiced by Amer F. Ahmed, too often universities forget that a huge part of social justice work is education, and using 'big, inaccessible words' that the public doesn't understand can perpetuate elitism rather than work to dismantle it. ${ }^{9}$

To craft the exhibition, we adapted each interview into an 800 -word narrative, composed using the participant's own words. This was inherently challenging, as what makes the human voice so powerful is that it is spontaneous and emotional, qualities which are easily lost when 
hours of recordings are condensed for clarity and length (Lowry and Duke 2015). When selecting direct quotations we worked to stay true to the tenor of each participant's interview, a point raised by Anna Green (2007) as essential to editing oral history for presentation purposes. We also shaped each narrative into a story arc (roughly: hook, source of marginalization, conflict or climax, and resolution). This method reinforced in some ways, rather than challenged, problematic ideas about knowledge. However, we strongly felt that crafting narratives using mainstream storytelling conventions would make the narratives accessible and relatable and mark the information as worthwhile to consider for the broadest possible audience.

One of us drafted each narrative, and the other compared it point-by-point to the full interview to ensure accurate representation of the participant's shared wisdom and experiences. After adjustments to address discrepancies, we sent each participant their narrative for review, emphasizing that they held final editing rights. Most participants did not request changes, instead writing, for example, 'Thank you for hearing me' and another 'I got emotional reading it'. While this positive feedback was gratifying, we were also pleased that six participants requested substantive changes to their narratives, with three more requesting minor changes. These assertions of rights to authorship reassured us that we had broken down at least some of the power hierarchies that can hamper community collaborations. We worked with each participant until they were satisfied with the final narrative. To further guarantee accountability, participants retain their right to withdraw their contributions from the project in its online and travelling form up through the present.

Each of the 42 narratives stood as an independent testimonial. At the same time, the multiplicity of distinct stories converging on a unifying theme reinforced the commonalities of the narratives and subtly illuminated the systemic nature of the challenges depicted. For example, 'Stones May Rot' (a theme title based on the Samoan proverb 'Stones may rot but words do not') grouped together narratives that spoke to the ways in which others' words affect self-perceptions and propel life decisions. The section featured stories highlighting experiences with obesity, the model minority myth, teen pregnancy, racism, English as a second language, and bipolar disorder. But the narratives also converged on the following

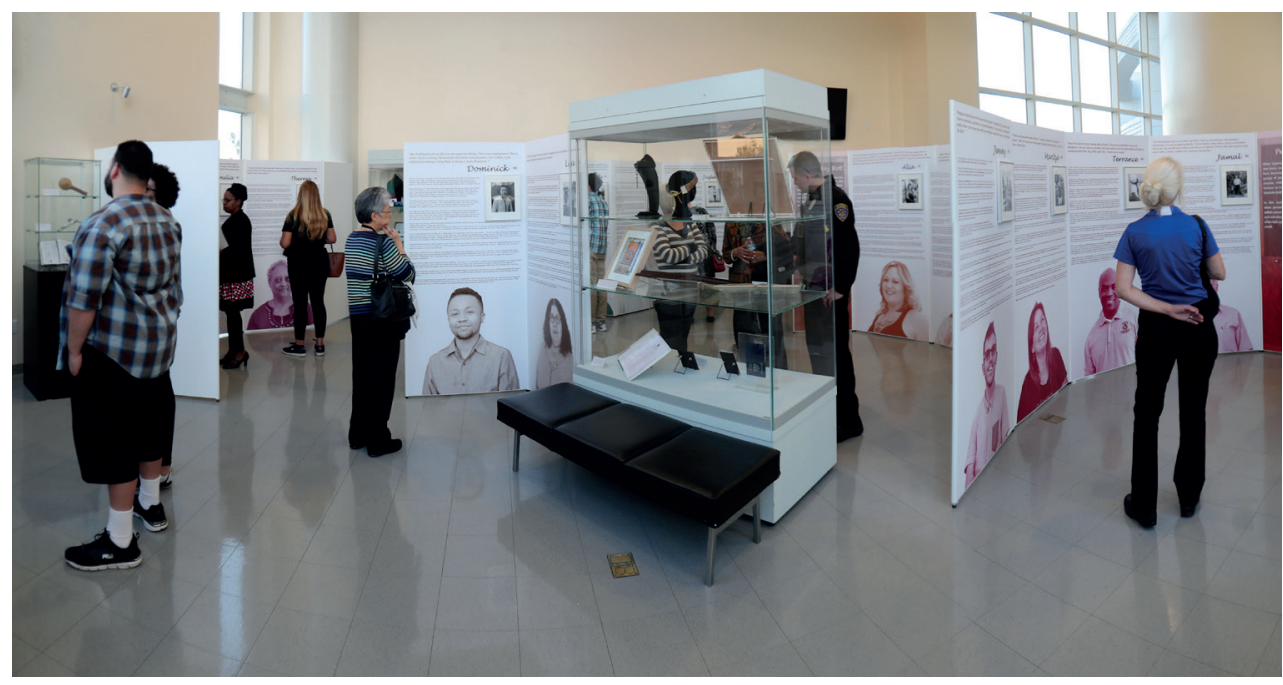

Photo 1: In|Dignity was on display at California State University San Bernardino from January to December 2018.

issues: educational systems failing to provide for non-traditional students, those in positions of power diminishing self-esteem of the marginalized, and biases that perpetuate inequitable biomedical care.

When developing the narratives we were mindful to avoid the production of a 'spectacle of suffering' (Bonnell and Simon 2007) which would degrade interviewees and render visitors 
"The hip-hop game is hard. It is. But I love the music, so I can't get away from it. They just have to deal with me and how I am, because I'm not changing nothing for nobody. I am not your Rubik's cube."

\section{D-Skyy 吸}

My name is Latoya. I' $m$ a mother, a daughter, a sister, and a really good triend. I'm also a community activist and a small business owner. My life is busy, but sometimes 1 lay awake at night knowing that there's always something more I can do. The world's
not going to change if we're sitting on our butts and twiddling our thumbs $I$ 'm the one not going to change if we're sitting on our butts and twiddling or
who steps out on a limb when there is no limb. That's me.

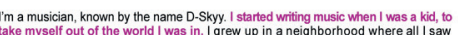
take myself out of the world I was in. I grew up in a neighborhood where all I saw
was violence. To shelter myself from all the stuff that was out there I just did music. My mom used to say, "Why are you being so wasteful?" She started limiting the amount of paper she would give me. So I would write music on the walls of the closet.

Music is therapy. Music is love. Music is passion. And it gives me so much.

As a rap artist I am part of the hip hop community, which is male dominated and very
directive as to what I am supposed to rap about. Women are supposed to say A, B, C, and $D$. Don't go past $D$. And I'm not supposed to be better than any guy, period.

In the industry and among fans there is also an expectation that, as a female rapper, ' 111 go half naked. There are two female rappers in history who have been successtu,

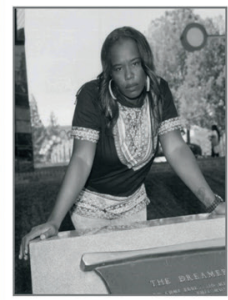

remember this one photo shoot of female artists from all over California and Arizona. lagreed to be involved until they sent over a description of what we had to wear - black or gold booty shorts, spandex, shirt cut down low

I'm just not that kind of girl. Nine times out of ten I'm in my chucks, my jeans, my sweatshirts, and my hoodios. I had my manager call the guy and he says, "Do you know
She's gotta show some skin."

There was another incident where I was booked for a show. We're at my house getting ready and the promoter calls and he says I have to curves." I hung up.

I'm not gonna change! For what? It's not gonna happen. I've got a homegirl who told me, "You know, ever since the third grade you have not changed." I like to hear that. Let me stick to my guns. Sex sells, I understand that. But my thing is, what are you teaching by doing that - by changed. "like to hear that. Let me 'stick to my guns. Sex sells, l understand that But my thing
telling little kids that if they aren't valued for their bodies they're not worth anything?

I have three daughters, and I'm real big on self-esteem. So I have this long mirror on the inside of my hallway closet, and before $m y$

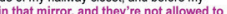

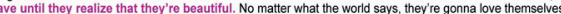

Sometimes it takes them awhile to leave the mirror, especially my daughter who has dark skin. In the Black community the different shades of

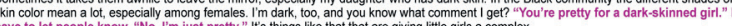

got a lot of flack for my complexion when I was a kid, and it made me angry! Back then, my reaction was just to punch a person in the face. People still expect me to pop off, to go crazy, to start yelling and fussing and cussing and fighting. I'm from the projects, so I'm supposed to

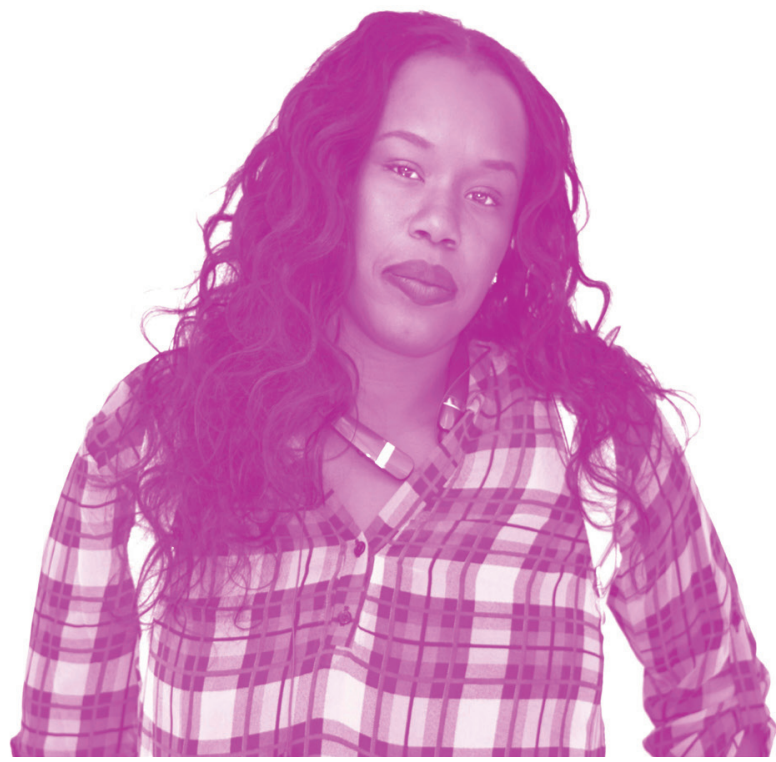

Photo 2: Exhibition panel for D-Skyy, one of 43 community members who participated in In|Dignity. as voyeurs. While raw, affective experiences of marginalization were central to the power of In|Dignity, each narrative offered (and arguably centred on) wisdom and insights that portrayed the participant's resilience, achievement, capacities, and overall worthiness of esteem and respect. This is not to be mistaken for a trope of 'try hard and you can overcome anything'. While the narratives did avoid defeatism, they simultaneously highlighted systemic forces of marginalization that made individual journeys challenging and ongoing, and they made clear that while each participant may have been shaped by hardships, they were not defined by them.

Each $\operatorname{In|}$ Dignity narrative was accompanied by a black and white portrait of the speaker prepared by CSUSB faculty member Tom McGovern, who specializes in documentary photography - a method of visual storytelling that aims to instigate social change by exposing unseen or ignored realities (Finnegan 2015). McGovern photographed In|Dignity participants with a 645 medium format film camera. Avoiding digital photography was intentional; utilizing a manual film camera requires contemplation on the part of both photographer and subject, and a conversation between them.

The technique also produces a physical negative that is both fragile and unique - just like humans. Participants were asked to select a location for their photo shoot that was meaningful to them. Over four months McGovern drove to each location and spent time getting to know participants before photographing them. McGovern's process thus not only produced sharp images with natural postures, but also embodied the humanistic relationship building that In|Dignity sought to promote. 
We additionally asked each participant to select an object to represent their identity, how others see them, or how they see themselves, and to provide a short explanation of their selection. Accommodating their choices meant reconsidering criteria for what counts as an object worthy of display and allowing for diverse interpretations and agendas to emerge rather than homogenizing them or forcing them to fit into a single storyline. This is consistent with best practices advocated by other curators who have incorporated community objects into museum displays (Lynch and Alberti 2010: 26).

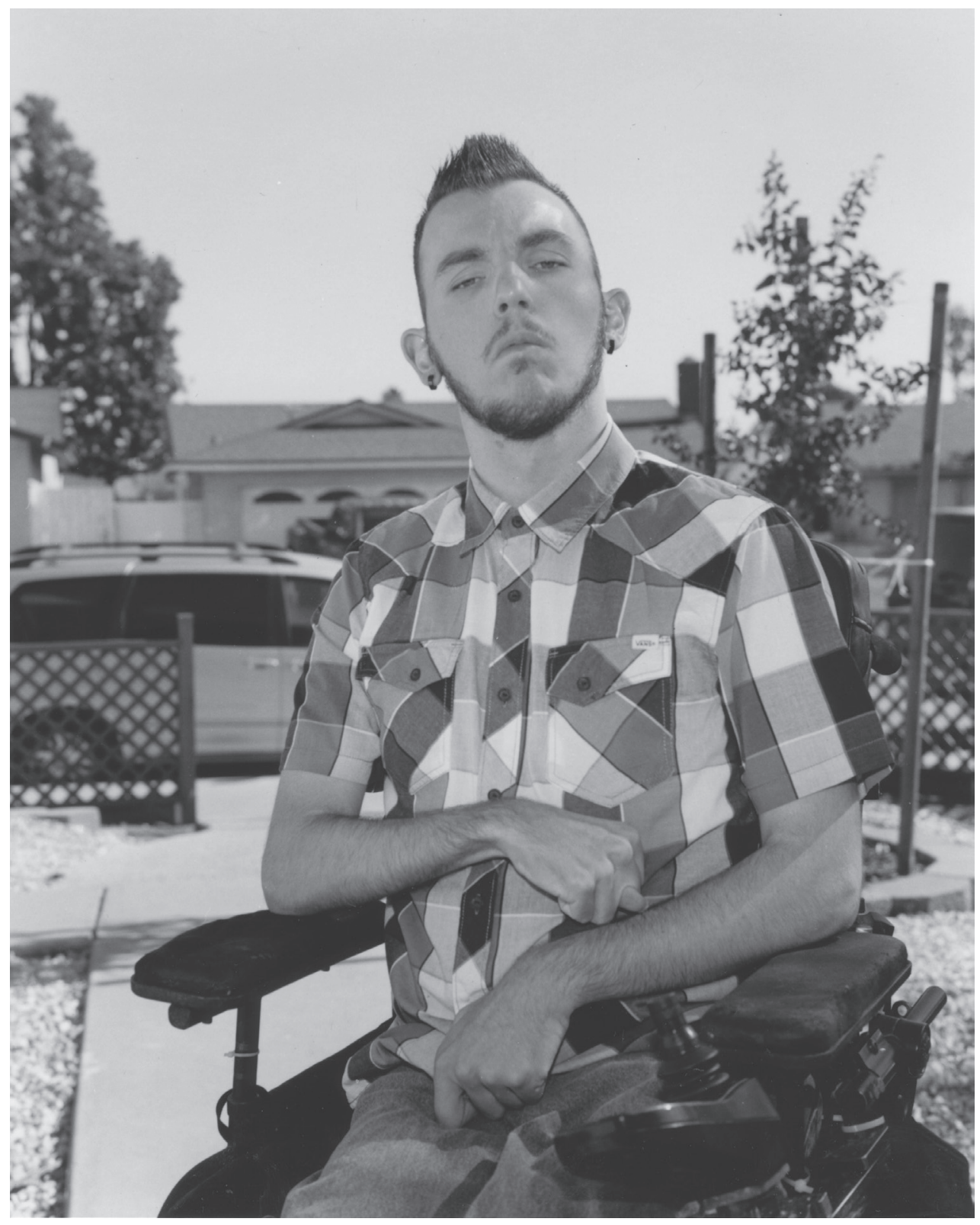

Photo 3: Portrait of Jeremy, one of 43 community members who participated in In|Dignity. Image by Tom McGovern. 


\section{Head Scarf}

\section{Maryam wears a scarf as a sign of modesty and her devotion to God.}

\section{"Some people look at my head scarf and tell me, 'Take if off! You don't need it. You're in America now.' And I'm like, 'I've been here almost my whole life, so I know what my rights are, thank you.' I am proud to wear it."}

\section{Photo 4: Object caption for Maryam's head scarf.}

Each participant was gifted a print of McGovern's portrait of them, the cache of digital images he took to warm up for the manual shots, and a full colour exhibition catalogue. We further honoured participants' stories through a collaboration with the CSUSB Department of Theatre Arts, in which students, community members, and faculty prepared a performance based on the narratives. ${ }^{10}$ The show was scripted and developed using techniques of devised theatre -a method for creating an original work through collaborative and improvisational participation by the entire company (Chemers 2010: 133-6). By using these techniques, the theatre ensemble aimed to replicate the objectives of the broader In|Dignity project not only in content but in methodology, abandoning credentialed expertise as a qualification for participation and uniting multiple voices for a common purpose. In|Dignity participants were among the audience members for the two performances, and they reported that the experience of having someone else utter their words on stage was cathartic and empowering. The actors also reported the impact of meeting the individuals they portrayed as humbling and inspiring.

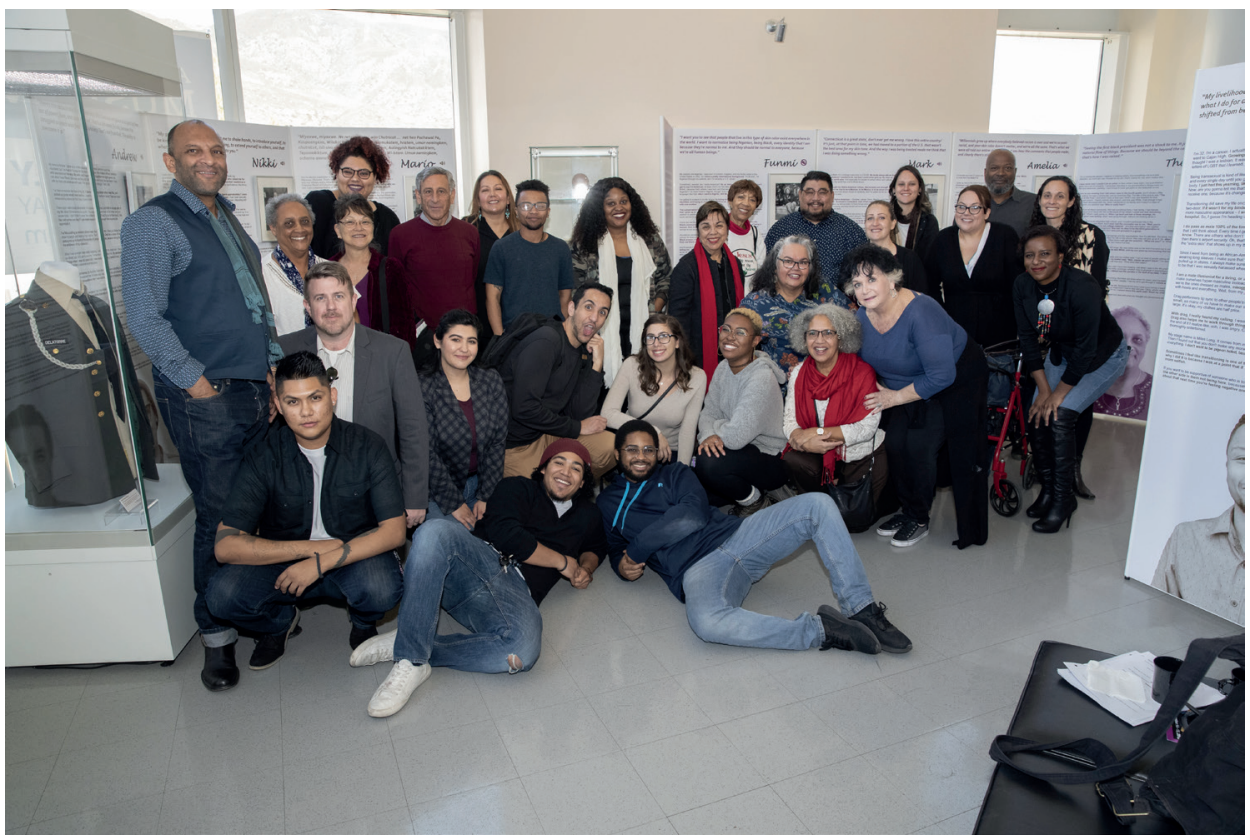

Photo 5: The theatrical team poses for a picture with some of the 43 In|Dignity participants and the In|Dignity curators at a closing reception. 
In|Dignity ran from January through December of 2018. The project, supported by California Humanities, a non-profit partner of the National Endowment for the Humanities, the Mervyn D. Dymally African American Political and Economic Institute and our campus Office of Community Engagement, was well attended by students, staff, school groups and community members. The exhibition also captivated our County Superintendent of Schools. Soon after his visit he commissioned a travelling version of In|Dignity to rotate among high schools, accompanied by a specially developed social studies curriculum aligned with state learning standards..$^{11}$ In this way, we were able to produce a community-defined public good, solicited to benefit the region rather than the individual participants, and to support county efforts to promote an anti-bullying agenda.

A second community-defined public good came at the request of CSUSB faculty members who sought help incorporating In|Dignity into their courses. To address this request the second author, together with CSUSB colleague Kelly Campbell (Psychology), created 'concept cards'. These double-sided, one-page handouts related exhibition content to current issues like immigration, disparities in the criminal justice system, and the 'me too' movement. Each card directed visitors to three narratives scattered throughout the exhibition and asked a series of questions aimed at sparking class discussions. The concept cards also included advice from participants on how to promote equity, justice, fairness and kindness - for example, simple acts like 'stepping outside of your daily routine' through participation in community events, but also fighting to 'level the field' and protest injustices.

While we did not conduct a formal exhibition evaluation, visitors left 613 messages in our comment book. The words 'moving', 'captivating' and 'inspirational' are prominent throughout, with many visitors sharing more extensive feedback indicating the depth of their reactions. For example, 'Perhaps the most powerful exhibit this University has hosted', '(This) display was an eye opener for me' and 'I'm deeply moved'. One visitor remarked, 'The museum really touched me. Reading through several stories made me realize the other struggles, problems, and experiences other humans have. All we need to do is unite as a community and appreciate each other's differences and talents'. According to another: 'Wow. This exhibit was empowering to say the least'. Community participants also left comments, including 'So proud to have been part of this', 'I'm incredibly grateful for this exhibit', and 'Thank you for allowing us to have a voice among others'. Two self-identifying museum professionals reflected on the effectiveness of the story-driven text for engaging visitors, one remarking, 'Even though the panels are text heavy, I want to read everything' and the other, 'I found it captivating the way everyone featured embodies their story, and the impact they had on me as I read them was just amazing'.

Visitor comments also record an impact that we did not anticipate: a sense of catharsis for those who went into In|Dignity feeling isolated. Toward the end of the exhibition's run one visitor provocatively wrote, 'l've been coming here for the past three weeks and if it [has] made me realize just one thing, it's that I am not alone'. Another visitor became emotional while viewing the exhibition. When approached by the first author (the museum director) the visitor explained that she had thought she was the only one in her situation (as an undocumented citizen facing harassment at work), but learned she was not. These anecdotes dovetail with observations by Annette Day (2006), whose oral-history based exhibition on London refugees inspired visitors with a refugee background to feel belonging and pride. Such responses are of particular importance because the capacity for museum exhibitions to enable marginalized individuals to find solidarity and relief (rather than just representation) is not prominent in museums and social justice literature (but, see Lonetree 2012, who argues that addressing painful aspects of history in museums can promote community healing). More attention is also needed to understand the potential power for storytelling-based exhibitions not just to represent communities, but also to create them (Witcomb 2007).

In|Dignity exploded common, narrow ideas of 'diversity' that limit its contours to race, gender, religion and sexuality. In|Dignity narratives addressed these themes, but they also explored class, ableism, cisgenderism, pronatalism, weightism, urban-rural tensions, the model minority myth, multiracial identities, discrimination within the LGBT community against BIPOC, the role of language in Hispanic identity, tensions in the black community between those born in Africa and in the diaspora, struggles to trace heritage for access to and acceptance within 
Native American communities, transgender experiences, modern slavery, child abuse, and marginalization due to teen pregnancy, mental health, homelessness, immigration status, and former incarceration. By eliciting and presenting individual biographies in a way that highlighted rather than truncated the uniqueness and the intersectionality of identities, and by illustrating ways in which perceived and actual differences shape opportunities and experiences in distinct but overlapping ways, In|Dignity forced the expansion of simplistic notions of 'diversity' and showcased the radical potential of museums working with the community - their community - to facilitate storytelling and story listening.

\section{Challenges and Reflections}

In this project we had many successes - measured anecdotally by the shared curatorial authority of our participants, the time visitors spent reading unusually long texts, the emotional outpouring in our comment book and community requests for public goods. There were also challenges, which we discuss with the intention of providing transparency, self-reflection, and insights for those who wish to take on similar narrative-based social justice curatorial projects.

One of the biggest challenges of In|Dignity was our academic affiliation. Regardless of how intentionally we attempted to share curatorial authority with participants, the letters 'PhD' intimidate many. Thus, while we would like to imagine that few participants requested substantive changes to their narratives because our methods effectively enabled participantdriven stories, societal dynamics would suggest that our degrees and faculty positions may have (also) played into an inherent power imbalance. This challenge is not easily remedied, but we attempted to counterbalance it through handing over editing rights and maintaining participants' rights to withdraw in perpetuity.

In retrospect, another option would have been to let participants take the lead with every step, including the process of thematic development and composition of text panels. While an aspirational ideal, this more extensive community involvement might also have deterred participation, especially from individuals with time and financial constraints and limited access to transportation. We also note that in museum-community collaborations, those individuals whom we ask to share their knowledge, whom we invite to participate as co-researchers, whom we train as a part of capacity building and whom we listen to when defining public goods, all represent 'the community', together and collaboratively, even where these circles of participants do not fully overlap. In our case involving over 300 students at a public university that draws from a broad variety of social groups was the form of capacity building that best met our institution's educational mission. However, in retrospect we wish that we would have more deliberately prioritized the development of community-defined public goods.

Another challenge was determining how to tell stories that centred on painful experiences while also recognizing the potential for offending visitors with explicit content. Overstimulating visitors with upsetting and difficult information can lead to desensitization (Nilsen and Bader 2017) or rejection of the information, and when those who identify with oppressors feel attacked, the educational intent of an exhibition can be lost (Cavness 2019). We were thus mindful of crafting an experience that would make people feel uncomfortable, but without putting them on the offensive. This was achieved, in part, by including experiences of a broad range of participants and highlighting the realities of intragroup as well as inter-group discrimination. The exhibition design also allowed for meandering (rather than a designated path), and ample lighting and muted colours helped to make the exhibition approachable.

Certain visitors felt excluded nevertheless. One openly complained to museum staff about the underrepresentation of individuals shut out from opportunities because of their conservative values (sometimes referred to as 'cancel culture'). A fair point, as museums are democratic public spaces where meanings are meant to be exchanged and negotiated (Giroux 2001), and centring counter-narratives does not demand exclusion of other perspectives. This particular confrontation could have perhaps been deescalated with more grace had we made a stronger effort to recruit individuals with conservative values as participants or developed a statement on the politics of inclusion and exclusion that offered an explanation of our decision to do otherwise. We acknowledge that presenting this exhibition at a university museum, where academic freedoms are generally respected, afforded us a capacity to not worry very much about 'whose sensibilities we may offend' (Adams 2017), which not all museums can do. 
We were also slow to take up the mantle of formal exhibition evaluation, and here we were certainly not alone. While museums typically judge the success of exhibitions through surveys, ticket sales, and exit interviews (Ellis 1995; Serrell 1997: 109), these instruments are woefully inadequate for measuring the emotional responses, attitudinal shifts, and sense of empowerment desired from many affective, collaborative, and community-based exhibitions (Sandell 2007; Hooper-Greenhill 2008) as well as gauging whether such effects endure (Gokcigdem 2016: 128). Even where visitors describe a personal impact, scholars (e.g. Westheimer and Kahne 2004) note that such self-reporting does not guarantee either the motivation or the capacity to act. The true effects of social justice exhibitions are likely to be more effectively measured through longitudinal studies, which museums, to date, have not been adept at designing or pursuing (Gokcigdem 2016: 128; Gonzales 2020: 133). Moreover, the end goal of systemic change, by its very nature, is too diffuse to measure with certainty.

Some museums intentionally guide their visitors to take specific actions to promote social justice such as signing petitions, calling a legislator, donating to a social cause, or registering to vote ( $\mathrm{Ng}$ et al. 2017; Gonzales 2020). ${ }^{12}$ In developing In|Dignity we struggled with the feeling that we, too, needed to offer concrete next steps to our visitors. But we also considered that too much emphasis on personal actions obscures the need for collective initiatives, distracts attention from systemic causes of disparities, and avoids politics and policy. In the end, we restricted such pointers to the concept cards, and delivered them only through the words of participants. We wonder if this was a missed opportunity to provide more prominent, extensive and specific information about what can be done to promote social justice through personal responsibility, participatory citizenship and justice-oriented collective actions (Westheimer and Kahne 2004).

A final challenge was creating a sense of community among In|Dignity participants, together with maintaining a connection between participants and the museum after the gallery exhibition closed. Our participants had no organizational structure or common identity that tied them together. They met one another at our receptions, but our efforts to protect confidentiality meant that they remained largely anonymous to one another. Setting up a secure communication channel that masked personal contact information may have helped to extend their relationships with one another and with the museum. As a result of casting our net so wide to recruit participants, we also ended up developing relationships (and friendships) with individuals, but not partnerships. In hindsight, working more directly with community organizations to identify some of our participants may have helped us to build connections that would outlast a single exhibition and have greater potential for impactful change.

\section{Conclusion}

In|Dignity was an experimental collaboration - not with a singular, marginalized group, but with the multifaceted and multi-layered community in which our museum is embedded. The project included faculty from three colleges and six departments, and over 300 undergraduate students from various disciplines. We infused our methodologies with a social justice agenda by flattening hierarchies, sharing authority, and broadening what counts as worthy of attention. In the end, by utilizing our resources, credentials, and privileges as university professors we were able to amplify stories from our community, widely sharing the experiences of 43 individuals, underscoring the legitimacy of their knowledge, the pervasiveness of injustice and the tolls of marginalization. With engaging narrative accounts, InDignity pulled visitors in, not by asking them to learn something about social justice but by creating the conditions for open-mindedness to its validity. In offering intimacy rather than certainty, and a relational mode of engaging with the content rather than the more typical museological approach of interpretation and analysis, In|Dignity incorporated, supported, and served the community by laying groundwork for critical consciousness and, we hope, also allyship and change.

With this article we intend to inspire those who are interested in similar communitymuseum collaborations, and particularly university museums with the opportunity to engage students, to consider the power of storytelling as a part of their endeavours (see also $\mathrm{Ng}$ et al. 2017; Orloff 2017). Community engagement and service learning are widely upheld as high impact practices in education, and working with oral histories is demonstrated to enhance 
student investment in course materials (Baxter and Marshall 2012: 62). Likewise, Norma González, Luis Moll, and Cathy Amanti (2005) argue that it is through such projects of deep engagement that educators themselves (and we can extend here to museum professionals) can become more effective allies for social justice. This was certainly our own experience. While we have both studied diversity from disciplinary perspectives (anthropology and sociology), we were astounded by the intersectional identities and dimensions of marginality reported by project participants. This enhanced our understanding of and appreciation for our community, and encouraged us to continue devoting our resources and skills to uplift local stories, support marginalized identities, and craft affective encounters with 'Others' to promote compassion, critical reflection, and ultimately systemic change in the museum, in the classroom, and in the world.

Received: 4 January 2021

Finally accepted: 24 March 2021

\section{Notes}

1 The previous ICOM definition of 'museum' stressed collections stewardship, research, and programming to support 'education, study and enjoyment'.

2 See also Seph Rodney, 'The Conflict Around Diversity at the American Alliance of Museums', Hyperallergic, 3 June 2016. https://hyperallergic.com/302752/the-conflictaround-diversity-at-the-american-alliance-of-museums/, accessed 27 December 2020, and Museums Association, 'Power and Privilege in the $21^{\text {st }}$ Century Museum: Tactics for Change from the Museums Association Transformers Programme', 2017. https:// www.museumsassociation.org/campaigns/power-and-privilege-21st-century-museum, accessed 27 December 2020.

3 Mary Carole McCauley, 'Baltimore Museum of Art Director Chris Bedford Tries to Change the World. So Why Does He Make Some People Angry?', Baltimore Sun, 20 November 2020. https://www.baltimoresun.com/entertainment/arts/bs-pr-fe-baltimore-museum-ofart-chris-bedford-20201120-zkltkjinr5f7vd4bidb4alvncy-story.html, accessed 1 March 2021.

4 Simona Bodo, Kirsten Gibbs, and Margherita Sani (eds), 'Museums as Places for Intercultural Dialogue: Selected Practices From Europe', MAP for ID Group, The British Museum 2009. https://www.ne-mo.org/fileadmin/Dateien/public/service/Handbook_MAPforlD_EN.pdf, accessed 27 December 2020.

5 Elizabeth Merritt, 'Trust Me, I'm a Museum', Center for the Future of Museums Blog, 3 February 2015. https://www.aam-us.org/2015/02/03/trust-me-im-a-museum/ accessed 27 December 2020.

6 Museums Association, 'Power and Privilege in the $21^{\text {st }}$ Century Museum'.

7 In|Dignity was reviewed and received human subjects approval by the Institutional Review Board (IRB) at California State University San Bernardino, study number FY2017-21, with recordings later certified as a publicly available secondary data set.

8 Associated Press, 'One Year After San Bernardino Attack, City Aims to Prevent Muslim Hate Crimes', The Guardian, 1 December 2016. https://www.theguardian.com/us-news/2016/ dec/01/san-bernardino-shooting-one-year-later-muslim-hate-crimes, accessed 9 March 2021.

9 Amer F. Ahmed, 'The Culture of Campus Social Justice Elitism', ACPA Commission for Social Justice Education Blog, 4 February 2014. https://acpacsje.wordpress.com/2014/02/04/ the-culture-of-campus-social-justice-elitism-by-amer-ahmed/, accessed 27 December 2020. 
10 We are grateful for the organizational labour of Kathryn Ervin, Andre Harrington, Jason Mann, and Leslie Bryan along with the crew of students and community members involved in the production and performance of In|Dignity: The Devised Performance.

11 The In|Dignity curriculum was developed in partnership with the Region 10 Content, Literacy, Inquiry, Citizenship (CLIC) Project, under the leadership of Barbara Lane, Liz Ramos and Francine Bettger. More information on CLIC can be found at https://californiahss.org/. The In|Dignity curriculum can be accessed at http://www.indignityexhibit.weebly.com.

12 See also Museums Association, 'Power and Privilege in the $21^{\text {st }}$ Century Museum'.

\section{References}

Adair, B., Filene, B. and Koloski, L. (eds) (2011) Letting Go?: Sharing Historical Authority in a User-Generated World, Philadelphia: The Pew Center for Arts and Heritage.

Adams, M. (2017) 'Deconstructing Systems of Bias in the Museum Field Using Critical Race Theory', Journal of Museum Education, 42 (3) 290-6.

Allport, G.W. (1954) The Nature of Prejudice, Cambridge: Beacon Press.

Arnold-de Simine, S. (2013) Mediating Memory in the Museum: Trauma, Empathy, Nostalgia, New York: Palgrave Macmillan.

Baxter, J.E. and Marshall, M.S. (2012) 'University Students and Local Museums: Developing Effective Partnerships with Oral History', Partnerships: A Journal of Service-Learning \& Civic Engagement, 3 (2) 59-77.

Bedford, L. (2010) 'Storytelling: The Real Work of Museums', Curator: The Museum Journal, 44 (1) 27-34.

(2014) The Art of Museum Exhibitions: How Story and Imagination Create Aesthetic Experiences, New York: Routledge.

Bell, L.A. (2010) Storytelling for Social Justice, New York: Routledge.

Bennett, T. (1995) The Birth of The Museum, New York: Routledge.

Bonnell, J. and Simon, R.I. (2007) '“Difficult” Exhibitions and Intimate Encounters', Museum and Society, 5 (2) 65-85.

Bruner, E.M. (1996) 'Tourism in Ghana: The Representation of Slavery and the Return of the Black Diaspora', American Anthropologist, 98 (2) 290-304.

Bruner, J. (1990) Acts of Meaning, Cambridge: Harvard University Press.

Cameron, F. (2007) 'Moral Lessons and Reforming Agendas: History Museums, Science Museums, Contentious Topics and Contemporary Societies', in Simon J. Knell, Suzanne MacLeod and Sheila Watson (eds) Museum Revolutions: How Museums Change and Are Changed, 330-42, Abingdon: Routledge.

Cavness, C. (2019) 'The Need for Diversity and Inclusion in Developing Narratives', Theory and Practice, 2. Unpaginated http://articles.themuseumscholar.org/tp vol2cavness.

Chemers, M.M. (2010) Ghost light: An Introductory Handbook for Dramaturgy, Carbondale, IL: Southern Illinois University Press. 
Cho, H. (2017) 'Navigating the Meanings of Social Justice, Teaching for Social Justice, and Multicultural Education', International Journal of Multicultural Education, 19 (2) 1-19.

Chynoweth, A., Lynch, B., Peterson K. and Smed, S. (eds) (2020) Museums and Social Change: Challenging the Unhelpful Museum, London: Routledge.

Day, A. (2006) 'London's Voices: Exhibiting Oral History', Oral History, 34 (2) 95-104.

(2009) “"They Listened to My Voice”: The Refugee Communities History Project and Belonging: Voices of London's Refugees', Oral History, 27 (1) 95-106.

Dovidio, J.F., Eller, A. and Hewstone, M. (2011) 'Improving Intergroup Relations Through Direct, Extended and Other Forms of Indirect Contact', Group Processes \& Intergroup Relations, 14 (2) 147-60.

Ellis, C. and Patti, C. (2014) 'With Heart: Compassionate Interviewing and Storytelling with Holocaust Survivors', Storytelling, Self, Society, 10 (1) 93-118.

Ellis, R. (1995) 'Museums as Change Agents', Journal of Museum Education, 20 (2) 14-7.

Finnegan, C.A. (2015) Making Photography Matter: A Viewer's History from the Civil War to the Great Depression, Urbana-Champaign, IL: University of Illinois Press.

Fischer, D., Anila, S. and Moore, P. (2017) 'Coming Together to Address Systemic Racism in Museums', The Museum Journal, 60 (1) 23-31.

Fraser, N. (1997) Justice Interruptus: Critical Reflections on the 'Postsocialist' Condition, New York: Routledge.

Freire, P. (1968) Pedagogy of the Oppressed, New York: Seabury Press.

Giroux, H.A. (2001) Public Spaces, Private Lives: Beyond the Culture of Cynicism, Lanham: Rowman \& Littlefield.

Gokcigdem, E.M. (ed) (2016) Fostering Empathy Through Museums, Lanham: Rowman \& Littlefield.

(ed) (2019) Designing for Empathy: Perspectives on the Museum Experience, Lanham: Roman \& Littlefield.

Golding, V. and Modest, W. (2013) Museums and Communities: Curators, Collections and Collaboration, London: Bloomsbury Academic.

Gonzales, E. (2020) Exhibitions for Social Justice, New York: Routledge.

González, N., Moll, L.C. and Amanti, C. (2005) Funds of Knowledge: Theorizing Practices in Households, Communities, and Classrooms, New York: Routledge.

Green, A. (2007) 'The Exhibition That Speaks for Itself: Oral history and Museums' in Sheila Watson (ed) Museums and Their Communities, 409-17, New York: Routledge.

Griffiths, G. (1989) 'Museums and the Practice of Oral History', Oral History, 17 (2) 49-52.

Heldke, L. (2006) 'The Radical Potential of Listening: A Preliminary Exploration', Radical Philosophy Today, 5 25-46. 
Hirzy, E.C. (1992) Excellence and Equity, Education and the Public Dimensions of Museums: A report from the American Association of Museums, Washington, D.C.: American Association of Museums.

Hooper-Greenhill, E. (1992) Museums and the Shaping of Knowledge, London: Routledge. (2008) Museums and the Interpretation of Visual Culture, London: Routledge.

Janes, R. and Sandell, R. (eds) (2019) Museum Activism, London: Routledge.

Jennings, G. and Jones-Rizzi, J. (2017) 'Museums, White Privilege, and Diversity: A Systemic Perspective', Dimensions, 18 (5) Special Edition 63-74.

Julius, C. (2008) '“Digging [D]eeper than the Eye Approves': Oral Histories and Their Use in the Digging Deeper Exhibition of the District Six Museum', Kronos, 34 (1) 106-38.

Karp, I., Kreamer, C.M. and Lavine, S.D. (eds) (1992) Museums and Communities: The Politics of Public Culture, Washington, D.C.: Smithsonian Institution.

Kushner, T. (2001) 'Oral History at the Extremes of Human Experience: Holocaust Testimony in a Museum Setting', Oral History, 29 (2) 83-94.

Langstraat, L. and Bowdon, M. (2011) 'Service Learning and Critical Emotion Studies: On the Perils of Empathy and the Politics of Compassion', Michigan Journal of Community Service Learning, 17 (2) 5-14.

Lonetree, A. (2012) Decolonizing Museums: Representing Native America in National and Tribal Museums, Los Angeles: University of California Press.

Lowry, S. and Duke, A. (2015) 'Foundling Voices: Placing Oral History at the Heart of an Oral History Exhibition', in Robert Perks and Alistair Thomson (eds) The Oral History Reader, third edition, 508-21, New York: Routledge.

Lynch, B. (2020) 'Neither Helpful Nor Unhelpful - A Clear Way Forward For the Useful Museum' in Adele Chynoweth, Bernadette Lynch, Klaus Peterson and Sarah Smed (eds) Museums and Social Change: Challenging the Unhelpful Museum, 1-32, London: Routledge.

Lynch, B. and Alberti, S.J.M.M. (2010) 'Legacies of Prejudice: Racism, Co-production and Radical Trust in the Museum', Museum Management and Curatorship, 25 (1) 13-35.

Mayo, P. (2013) 'Museums as Sites of Critical Pedagogical Practice', Review of Education, Pedagogy and Cultural Studies, 35 (2) 144-53.

McDonnell, J.A. (2003) 'Documenting Cultural and Historical Memory: Oral History in the National Park Service', Oral History Review, 30 (2) 99-109.

Momaya, M., (2018) 'Ten Principles for an Anti-Racist, Anti-Orientalist, Activist Approach to Collections', in Elizabeth Wood, Rainey Tisdale and Trevor Jones (eds) Active Collections, 13-20, New York: Routledge.

Ng, W., Ware, S.M. and Greenberg, A. (2017) 'Activating Diversity and Inclusion: A Blueprint for Museum Educators as Allies and Change Makers', Journal of Museum Education, 42 (2) 142-54.

Nilsen, A.P. and Bader, M. (2017) 'The Psychology of Empathy: Compelling Possibilities for Museums', in Elif Gokcigdem (ed) Fostering Empathy in Museums, 115-30, London: Rowman \& Littlefield. 
Nightingale, E. and Sandell, R. (2012) 'Introduction to Museums, Equality, and Social Justice', in Richard Sandell and Eithne Nightingale (eds) Museums, Equality, and Social Justice, 1-10, New York: Routledge.

North, C.E. (2006) 'More Than Words? Delving into the Substantive Meaning(s) of "Social Justice" in Education', Review of Educational Research, 76 (4) 507-35.

Orloff, C. (2017) 'Forum: Should Museums Change Our Mission and Become Agencies of Social Justice?', Curator: The Museum Journal, 60 (1) 33-6.

Peers, L.L. and Brown, A.K. (2003) Museums and Source Communities: A Routledge Reader, London: Routledge.

Perks, R. (1991) 'Ellis Island Immigration Museum, New York', Oral History, 19 (1) 79-80.

Pettigrew, T.F. and Tropp, L.R. (2006) 'A Meta-Analytic Test of Intergroup Contact Theory', Journal of Personality and Social Psychology, 90 (5) 751-83.

Reilly, M. (2018) Curatorial Activism: Toward an Ethics of Curating, London: Thames \& Hudson.

Roberts, L. (1997) From Knowledge to Narrative: Educators and the Changing Museum, Washington, D.C.: Smithsonian Books

Sandell, R. (2002) 'Museums and the Combatting of Social Inequality: Roles, Responsibilities, Resistance', in Richard Sandell (ed) Museums, Society, Inequality, 3-23, New York: Routledge.

(2007) Museums, Prejudice, and the Reframing of Difference, New York: Routledge.

(2012) 'Museums and the Human Rights Frame', in Richard Sandell and Eithne Nightingale (eds) Museums, Equality, and Social Justice, 195-215, New York: Routledge.

Serrell, B. (1997) 'Paying Attention: The Duration and Allocation of Visitors' Time in Museum Exhibitions', Curator, 40 (2) 108-25.

Simon, R.I. (2011) 'A Shock to Thought: Curatorial Judgment and the Public Exhibition of 'Difficult Knowledge', Memory Studies, 4 (4) 432-49.

Solórzano, D.G. and Yosso, T.J. (2002) 'Critical Race Methodology: Counter-Storytelling as an Analytical Framework for Education Research', Qualitative Inquiry, 8 (1) 2344.

Teslow, T. (2007) 'A Troubled Legacy: Making and Unmaking Race in the Museum', Museums and Social Issues, 2 (1) 11-44.

Tongo, N. (2006) 'A Critical Analysis of Oral History Methods in Collecting Memories of the Past: A Case Study of the Robben Island Museum Ex-Political Reference Group Project: Oral history in Museums', South African Museums Association Bulletin, 32 (1) $60-4$.

Wagaman, M.A., Obejero, R.C., and Gregory, J.S. (2018) 'Countering the Norm, (Re) authoring Our Lives', International Journal of Qualitative Methods, 17 (1) 1-11.

Watson, S. (ed) (2007) Museums and Their Communities, New York: Routledge.

Westheimer, J. and Kahne, J. (2004) 'Educating the "Good" Citizen: Political Choices and Pedagogical Goals', PS: Political Science \& Politics, 37 (2) 241-47. 
Witcomb, A. (2003) Re-Imagining the Museum: Beyond the Mausoleum, New York: Routledge.

(2007) '“A Place for All of Us"?: Museums and Communities", in Sheila Watson (ed) Museums and Their Communities, 133-56, New York: Routledge.

Zak, P. (2015) 'Why Inspiring Stories Make Us React: The Neuroscience of Narrative', Cerebrum, 2015 https://www.ncbi.nlm.nih.gov/pmc/articles/PMC4445577/.

\section{Authors}

\section{Arianna Huhn}

Arianna Huhn earned a MA in Museum Studies from George Washington University, and a PhD in Anthropology from Boston University. She is currently an Associate Professor of Anthropology at California State University, San Bernardino and Director of the university's Anthropology Museum. She previously participated in coordinating diversity, equity, and inclusion efforts at the American Alliance of Museums, designed exhibitions for the Port Discovery Children's Museum in Maryland, and served as Registrar for the San Diego History Center in California. Curated exhibits include Re|Collect, In|Dignity, Lost and Found, and the permanent exhibition at Museu Local in Metangula, Mozambique.

Postal address: 5500 University Parkway/San Bernardino, CA 92407 USA *

Email address: ahuhn@csusb.edu

Telephone number: +001 909-537-5505 *

\section{Annika Anderson}

Annika Anderson is an Associate Professor in the Department of Sociology at California State University, San Bernardino. Dr. Anderson is also the Executive Director of Project Rebound, a campus-based reentry program that recruits and retains formerly incarcerated students by providing wrap-around services. She received her BA in Public Relations from Pennsylvania State University and her MA and PhD. in Sociology from Washington State University. Her research interests are in criminology, social stratification, desistance, reentry, race and ethnic relations. She has presented research at academic conferences and has several publications on crime and re-entry based on research conducted in San Bernardino.

Postal address: 5500 University Parkway/San Bernardino, CA 92407 USA *

Email address: annika.anderson@csusb.edu

Telephone number: +001 909-537-7658 